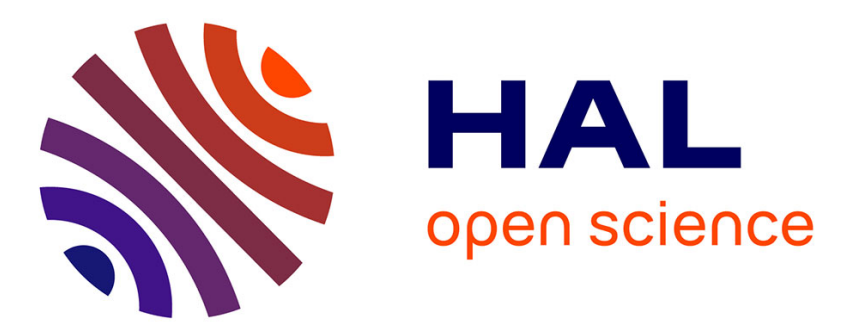

\title{
Practical equivalent control in 2-sliding controls applied to an anthropomorphic robot arm
}

\author{
Karim Braikia, Pascal Acco, Bertrand Tondu, Mourad Chettouh
}

\section{To cite this version:}

Karim Braikia, Pascal Acco, Bertrand Tondu, Mourad Chettouh. Practical equivalent control in 2-sliding controls applied to an anthropomorphic robot arm. 2010 IEEE/ASME International Conference on Advanced Intelligent Mechatronics (AIM), Jul 2010, Montreal, Canada. 10.1109/AIM.2010.5695740 . hal-01886025

\section{HAL Id: hal-01886025 \\ https://hal.laas.fr/hal-01886025}

Submitted on 11 Jan 2019

HAL is a multi-disciplinary open access archive for the deposit and dissemination of scientific research documents, whether they are published or not. The documents may come from teaching and research institutions in France or abroad, or from public or private research centers.
L'archive ouverte pluridisciplinaire $\mathbf{H A L}$, est destinée au dépôt et à la diffusion de documents scientifiques de niveau recherche, publiés ou non, émanant des établissements d'enseignement et de recherche français ou étrangers, des laboratoires publics ou privés. 


\title{
Practical Equivalent Control in 2-Sliding Controls Applied to an Anthropomorphic Robot Arm
}

\author{
Karim Braikia, Pascal Acco, Bertrand Tondu and Mourad Chettouh
}

\begin{abstract}
Driving an anthropomorphic robot arm driven by pneumatic artificial rubber muscles (PARMs) with a direct transmission is quite delicate. PARMs present complex nonlinearities and robust control tools are unevitable. Among them, those applied are the twisting and super twisting algorithms, which belong to the 2 -higher order sliding mode control set. In this paper it is studied the effect of the equivalent control in sliding mode controller based on variable structure systems (VSS) theory. It will be shown when to use the equivalent control, and the effects of a noisy sensor signal on control performance. Experimental results are presented and discussed.
\end{abstract}

\section{INTRODUCTION}

Driving a robot manipulator with direct transmission is a difficult task, mainly because of coupling effect, gravity, payload variation and actuator characteristics. The PARMs have some good properties [4] such as lightweight and low price. They also present compliance and bio mimetic properties. This compliance is of great interest when such an arm is used in human shared environments. There is renewed interest for flexible manipulators driven by PARMs in several applications [5]. Nevertheless, a PARM present complex nonlinearities. Its force generation is nonlinear and it is subject to hysteresis [6] [7] and [8]. Artificial muscle characteristics vary with an increasing duty cycle [9], airflow properties and servo valves add to nonlinearities, see [10] for more details. A PARM is thus a naturally high nonlinear actuator and is difficult to model. The applied conrol technique must fulfil two necessities:

- Avoid both a complex model and a complex controller, which are not practical

- Robustness of the manipulator control against unknown parameters variations and modelling approximation

Control under heavy uncertainty conditions remains one of the main subjects of modern control theory. The sliding mode control (SMC) approach requirement is robustness against modelling errors. The idea is to introduce a new dynamic by imposing a switching surface. When sliding is reached, the system will become insensitive to parameter variations, modelling error and matched disturbances. These properties are very powerful tool in realizing a practical controller for either Single Input Single Output (SISO) or Multi Input Multi Output (MIMO) systems. The SMC allows the consideration of the mutual interaction of the joints

K. Braikia ${ }^{1}$, B.Tondu ${ }^{2}$ and Pascal Acco ${ }^{3}$ are with Departement of Electrical Engineering, and Computer Science, INSA Toulouse, 31400 Toulouse, France ${ }^{1}$ braikia.karimeetud.insa-toulouse.fr and $\left\{{ }^{2}\right.$ bertrand.tondu, ${ }^{3}$ pascal.acco\}einsa-toulouse.fr M.Chettouh is with the Department of Mechanical Engineering, University of Saad dahlab, 09000 Blida, Algeria chettouh@yahoo. com of robot as a disturbance and the definition of each joint of the manipulator as a SISO system. However the main drawback of standard SMC is mainly related to the chattering effect caused by the high-frequency control switching [11]. Chattering effect can deteriorate physical components and excite high frequency dynamics [12].

To overcome the above difficulties, the first idea is to add an equivalent control of a classical form of the SMC [13] and [14]. The other approach is to introduce higher order sliding mode in order to reduce chattering [15] and [16] while increasing accuracy in sliding [17]. Although control can be satisfied without the use of the equivalent control [18]. The usual control based on sliding mode is the sum of both controls: equivalent and sliding discontinous control [13] and [14].

In the following, two well known 2-sliding control laws are studied: the twisting and super twisting algorithms [19], [20], [21], and [17]. The effect of equivalent control on regulation performance under heavy uncertainty will be shown. Its use in some cases is beneficial and can in others lead to performance degradation. It will also be shown when to use this equivalent control. Furthermore, the effect of a noised sensor signal on control performance is also addressed.

The paper is organized as follows: first the experimental set up is presented together with the actuator, the model identification is presented in section II. Then, the two 2-sliding algorithms previously indicated are established. Analysis of the use of the equivalent control and the effect of a noisy sensor signal on 2-sliding algorithms then follow. Finally, results are discussed and conclusions drawn.

\section{RoBOt AND ACTUATOR}

The control approach described in this paper has been tested on the anthropomorphic robot arm (Fig.1). Located at the Departement of Electrical Engineering of INSA de Toulouse. It consist of 7 degrees of freedom (d.o.f), each joint is driven by a pair of PARMs [7] [8], assembled in an antagonistic posture, through the application of a pressure variation $\triangle P$ upon an initial pressure $P_{0}$ (Fig.2). The torque generated by a pair of PARMs may be written as:

$$
\Gamma=A\left(k_{1} \Delta P-k_{2} \theta\right)
$$

$A, k_{1}$ and $k_{2}$ are constant parameters depending on muscle geometry [8]. The first term of (1) is the driving component proportional to pressure variation $\triangle P$, while the second one is the restoring torque of a spring like stiffness $A k_{2}$, which actually is the compliance term where $\theta$ represents 


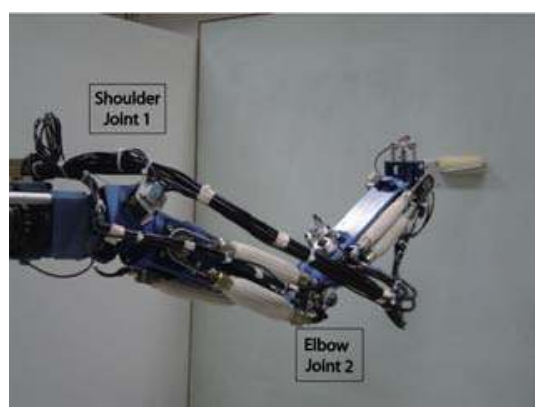

Fig. 1. The 7 d.o.f flexible robot arm

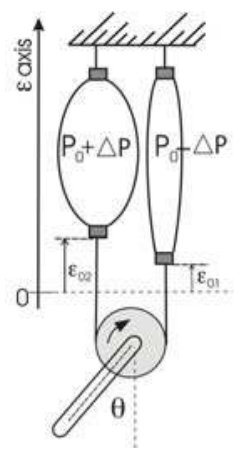

Fig. 2. Two PARMs in antagonistic posture

the angular displacement. It is worth noting that the system is open loop stable.

There are, on each joint, analog resistive sensors but no pressure sensors to monitor internal muscle pressure. The Intensity/Pressure (I/P) converter is supposed to be linear, which is not always true [22]. The PARMs used are developed within the LATTIS robotics laboratory at INSA Toulouse.

\section{A. Model synthesis}

In this application, two regional joints are controlled in regulation: Joint 1 (shoulder) and Joint 2 (elbow). The dynamic description based on generalized forces is:

$$
J \ddot{\theta}+h(\theta, \dot{\theta})+g(\theta)=\Gamma(u, \theta, \dot{\theta})
$$

Where $\theta$ and $\dot{\theta}$ are respectively the angular position and velocity vectors, $\mathrm{J}$ is the inertia related matrix, $\mathrm{h}(\theta, \dot{\theta})$ is the vector of centrifugal, coriolis, and friction terms. $g(\theta)$ is the vector of gravity terms and $\Gamma(u, \theta, \theta)$ is the torque input

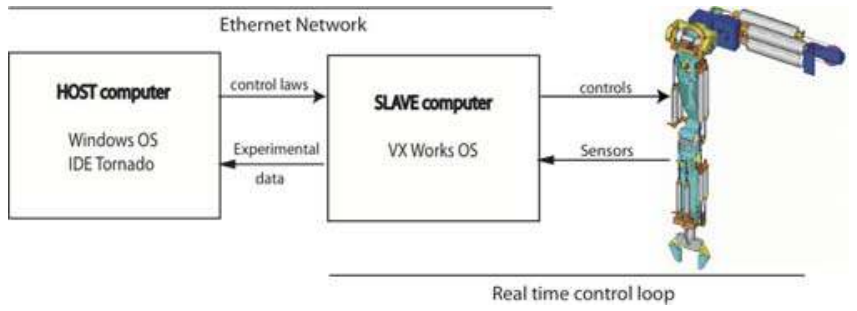

Fig. 3. Robot control architecture vector, $u$ is the control vector such that $\triangle P_{i}=f_{p}\left(u_{i}\right)$, where $f_{p}$ represents the transfer function of I/P.

Identification is carried out in open loop without payload, control step variations are applied to both joints in order to bring out the existing coupling effect. Joint dynamics is based on the estimation of coefficients of a supposed linear model. Sliding mode enables the assumption of decoupled manipuator joint (SISO). The joints interaction may be regarded as an external perturbation. The best linear curve to a presumed SISO input/output data $(u / \theta)$ is obtained by using Idproc of Matlab. The two joints coefficients average values as well as their percentage variations are indicated in table I. The transfer function for a delayed joint is:

$$
\frac{\theta_{i}}{u_{i}}=\frac{k_{i}}{1+2 \zeta_{i} \tau_{i} s+\tau_{i}^{2} s^{2}} \cdot e^{-t_{i} s}, i=\{1,2\}
$$

TABLE I

AVERAGE MODEL PARAMETERS VALUES

\begin{tabular}{|c|c|c|}
\hline parametres & joint 1 & joint 2 \\
\hline \hline$\tilde{k}_{i}(\mathrm{rad} / \mathrm{bar})$ & $0.31 \pm 7 \%$ & $0.48 \pm 40 \%$ \\
$\tilde{\tau}_{i}\left(s^{-1}\right)$ & $0.16 \pm 10 \%$ & $0.10 \pm 39 \%$ \\
$\tilde{\zeta}_{i}$ & $0.85 \pm 11 \%$ & $0.31 \pm 21 \%$ \\
$\tilde{t}_{i}(\mathrm{~s})$ & $0.18 \pm 26 \%$ & $0.06 \pm 31 \%$ \\
\hline
\end{tabular}

The resulting model coefficients variations estimations show that joint 2 is significantly influenced by the joint 1 dynamics, the opposite is not true. Model parameters variations separating a $0 \mathrm{Kg}$ from a $0.5 \mathrm{Kg}$ payload are indicated in table II. As it may be noted joint 2 is a lot more sensitive to payload variation (approximately $60 \%$ ) than joint 1 . This strengthens the need to resort to robust control. Also, in the following, hysteresis is not considered, as only increasing pressure/response data was used and delay is also considered as included in the overall model uncertainties.

TABLE II

PARAMETERS VARIATIONS SEPARATING 0KG FROM 0.5KG PAYLOADS

\begin{tabular}{|c|c|c|}
\hline parametres & joint 1 & joint 2 \\
\hline \hline$\tilde{k}_{i}(\mathrm{rad} / \mathrm{bar})$ & $-4.83 \%$ & $-9.14 \%$ \\
$\tilde{\tau}_{i}\left(s^{-1}\right)$ & $8.23 \%$ & $-23.80 \%$ \\
$\tilde{\zeta}_{i}$ & $15.18 \%$ & $233.91 \%$ \\
$\tilde{t}_{i}(\mathrm{~s})$ & $8.53 \%$ & $9.01 \%$ \\
\hline \hline average variation & $9 \%$ & $68 \%$ \\
\hline
\end{tabular}

\section{SECOND ORDER SLIDING MODES}

The principle of sliding mode control is to get the state to reach and remain on a predefined function named sliding surface $(\sigma)$ or manifold through discontinuous feedback [14] and [13]. Given a nonlinear system:

$$
\left\{\begin{array}{l}
\dot{x}=f(x, t)+g(x, t) u \\
y=\sigma(x, t)
\end{array}\right.
$$

$$
\{x, f(x, t)\} \in \mathbb{R}^{n}, g(x, t) \in \mathbb{R}^{n \times m}, u \in \mathbb{R}^{m}
$$


Where $x$ is the state variable, $t$ is time and $u$ the control. $f(x, t)$ and $g(x, t)$ are smooth uncertain functions and $\sigma(x, t)$ the smooth output is the sliding function. The discontinuous control is:

$$
u= \begin{cases}u^{+} & \text {if } \sigma(x, t)<0 \\ u^{-} & \text {if } \sigma(x, t)>0\end{cases}
$$

This control law has proven its robustness versus system parameters variations, modelling uncertainties and matched perturbations. It, however, engenders chattering that can degrade performance and may even deteriorate physical components [14] and [12]. In order to attenuate chattering, High Order Sliding Modes (HOSM) controls have shown their capabilities by driving the chatter back onto the higher time derivatives of the sliding manifold [16], [17] and [14]. The actual control is the output of cascading integrators. This enables to keep the main advantages of classical 1-sliding and at the same time reduce chatter and increase sliding precision [17]. Given a constraint function $\sigma(x, t)=0$, the $r$-sliding set is defined as:

$$
\sigma_{r}=\left\{x \in \mathbb{R}^{n} \mid \sigma(x, t)=\dot{\sigma}(x, t)=\ldots=\sigma^{(r-1)}(x, t)=0\right\}
$$

Moreover, in real sliding with a finite sampling time $\lambda$, sliding precision is up to the $r$ th order with respect to $\lambda$, i.e. $|\sigma|=O\left(\lambda^{r}\right)$. Given, without loss of generality, a SISO nonlinear system:

$$
\left\{\begin{array}{l}
\dot{x}=f(x, u, t) \\
y=\sigma(x, t)
\end{array} \quad u=U(x, t) \in \mathbb{R}\right.
$$

$f(x, u, t)$ is a smooth uncertain function with $\frac{\partial}{\partial u} f(x, u, t) \neq 0$ and the smooth output is the sliding variable. If the sliding variable is chosen, as often, to be a first order dynamics:

$$
\sigma_{i}(x, t)=c_{i} e_{i}+\dot{e}_{i}, \quad i=\{1,2\}
$$

Where $c_{i}>0$ and $e_{i}=\theta_{i}-\theta_{d_{i}}$ is the error, the dynamics of system equation (7) satisfies a 2-sliding set equation (6).

With respect to $\sigma(x, t)$ if the Filippov set of state trajectories lie in the space tangential to the intersection of $\sigma(x, t)=0$ and $\dot{\sigma}(x, t)=0$ [23]. The relative degree of the considered system equation (3) with respect to $\sigma(x, t)$ is 1 , as $\frac{\partial}{\partial u} \sigma(x, t) \neq 0$. Time derivation of $\sigma(x, t)$ yield:

$$
\begin{gathered}
\ddot{\sigma}=\zeta(x, t)+\psi(x, t) \dot{u}(t) \\
\zeta(x, t)=\frac{\partial}{\partial t} \dot{\sigma}(x, t, u)+\frac{\partial}{\partial x} \dot{\sigma}(x, t, u) f(x, u, t) \\
\psi(x, t)=\frac{\partial}{\partial u} \dot{\sigma}(x, t, u)
\end{gathered}
$$

The new discontinuous control is $v(t)=\dot{u}(t)$. Assuming the new control $v(t)$ is bounded by $v_{m} \in \mathbb{R}^{+}$, that $\zeta(x, t)$ and $\psi(x, t)$ are bounded uncertain functions with $\psi(x, t) \in \mathbb{R}^{+}$, then there exist positive constants $K_{m}, K_{M}$ and $C_{0}$ such that:

$$
0<K_{m} \leq \psi(x, t) \leq K_{M} \text { and }|\zeta(x, t)| \leq C_{0}
$$

If local coordinates $\left(z_{1}, z_{2}\right)^{T}=(\sigma, \dot{\sigma})^{T}$ are considered, then the 2-sliding problem is actually a finite time stabilisation of the second order auxiliary system described by:

$$
\left\{\begin{array}{l}
\dot{z}_{1}=z_{2} \\
\dot{z}_{2}=\zeta(x, t)+\psi(x, t) v(t)
\end{array}\right.
$$

Two control laws able to stabilise system equation (11) in finite time are the twisting [21] and super twisting [19] algorithms.

\section{A. Twisting law}

The twisting algorithm is given by:

$$
v(t)= \begin{cases}-u & \text { if }|u|>U_{M} \\ -A_{m} \operatorname{sign}\left(z_{1}\right) & \text { if } z_{1} z_{2} \leq 0, \text { and }|u| \leq U_{M} \\ -A_{M} \operatorname{sign}\left(z_{1}\right) & \text { if } z_{1} z_{2}>0, \text { and }|u| \leq U_{M}\end{cases}
$$

Where $U_{M}$ is the bound of the effective control applied to the system and the sufficient conditions for finite time convergence are:

$$
0<A_{m}<A_{M}, \quad A_{m}>\frac{C_{0}}{K_{m}}, \quad K_{m} A_{M}-C_{0}>K_{M} A_{m}+C_{0}
$$

The applied control is thus: $u_{t w}=\int v(t) d t$

\section{B. Super twisting law}

The super twisting algorithm is a superposition of two components:

$$
\begin{gathered}
u_{s t w}=\int \dot{u}_{1}(t) d t+u_{2}(t) \\
\dot{u}_{1}= \begin{cases}-u & \text { if }|u|>U_{M} \\
-w \operatorname{sign}\left(z_{1}\right) & \text { if }|u| \leq U_{M}\end{cases} \\
u_{2}= \begin{cases}-\alpha \varepsilon_{0}^{\rho} \operatorname{sign}\left(z_{1}\right) & \text { if }\left|z_{1}\right|>\varepsilon_{0} \\
-\alpha\left|z_{1}\right| \rho \operatorname{sign}\left(z_{1}\right) & \text { if }\left|z_{1}\right| \leq \varepsilon_{0}\end{cases}
\end{gathered}
$$

Where $U_{M}$ is the bound of the effective control applied to the system and $\varepsilon_{0}>0$ is the linearity bandwidth around the sliding surface $\sigma$. The sufficient conditions for finite time convergence are:

$$
w>\frac{C_{0}}{K_{m}}, \quad \alpha^{2} \geq \frac{4 C_{0} K_{M}\left(w+C_{0}\right)}{K_{m}^{2} K_{m}\left(w-C_{0}\right)}, \quad 0<\rho \leq 0.5
$$

\section{Equivalent control in sliding mode}

The control [14] and [13] is of the form:

$$
u=u_{e q}+\triangle u
$$

Where $u_{e q}$ is a equivalent control, $\triangle u$ is either twisting $u_{t w}$ as defined in (12), super twisting $u_{s t w}$ as defined in (13).

The equivalent control, when ideal sliding is realised, will take the state trajectory to the equilibrium position. The effect of $u_{e q}$ depends of the good estimation of the model parameters. However, it is unable to overcome in the system errors of modelisation and as it depends on the presumed model; if the latter is too far from the real model, it will induce undesirable performance.

The equivalent control can be written as:

$$
u_{e q}=\tilde{u}_{e q}+\triangle u_{e q}
$$


Where $\tilde{u}_{e q}$ is the estimated equivalent control and $\triangle u_{e q}$ represents the uncertainty in the equivalent control. Both quantities are linked to a presumed model and parameters uncertainties estimation. In order to compensate these uncertainties, the real control takes the form:

$$
u=\tilde{u}_{e q}+\triangle u
$$

Where $\tilde{u}_{e q}$ represents a continuous low frequency component supposedly able to keep the state trajectory on the switching surface once it is reached, whereas $\Delta u$ is a high frequency component able to ensure surface attraction despite uncertainties $\triangle u_{e q}$. In (17) $\triangle u$ takes the forms of either the twisting or super twisting controls. If the uncertainties cannot be compensated by $\triangle u$, i.e. $-\triangle u_{e q}+\triangle u \neq 0$, convergence conditions (10) may not be satisfied.

twisting control (12) results in an integration of a discontinuous control. If twisting does not compensate model uncertainties in equation (17), the action $\triangle u$ term looses its efficiency and convergence conditions (10) may not be satisfied.

Now, super twisting control (13) appears to be more interesting than twisting as it does not need to use $\dot{\sigma}(e, \dot{e})$; moreover, its control comprises a continuous term added to a discontinuous one. Again, if $\triangle u$ does not compensate model uncertainties in equation (17), the action of the discontinuous term looses its efficiency and convergence conditions may not be satisfied. As shown in the next section.

\section{EFFECT OF NOISE ON CONTROL}

Let us now consider a noised position sensor:

$$
\theta_{\eta_{i}}=\theta_{i}+\eta
$$

Where $\eta$ is a white noise. Then sliding manifold $\sigma_{i}$ may be rewritten as:

$$
\sigma_{i}=c_{i} e_{i}+\dot{e}_{i}+\left(c_{i} \eta+\dot{\eta}\right), \quad e_{i}=\theta_{i}-\theta_{d_{i}}
$$

The twisting control (12) is less sensitive to noise than the super twisting control as the integration attenuates chatter due to noise as well as smoothing the control. In the super twisting control (13), it is the discontinuous component $u_{2}(t)$ that may degrade performance.

$$
u_{2}= \begin{cases}-\alpha \varepsilon_{0}^{\rho} \operatorname{sign}\left(z_{1}\right) & \text { if }\left|z_{1}\right|>\varepsilon_{0} \\ -\alpha\left|z_{1}\right|^{\rho} \operatorname{sign}\left(z_{1}\right) & \text { if }\left|z_{1}\right| \leq \varepsilon_{0}\end{cases}
$$

The presence of $\dot{\eta}$ in the expression of $z_{1}=\sigma(e, \dot{e})$ may deteriorate performance, so the linearity bandwidth $\varepsilon_{0}$ has to be chosen small in order to avoid using $u_{2}(t)=$ $-\alpha\left|z_{1}\right|^{\rho} \operatorname{sign}\left(z_{1}\right)$. In which case, when outside $\varepsilon_{0}$, the constant amplitude discontinuous action $u_{2}(t)=-\alpha \varepsilon_{0}^{\rho} \operatorname{sign}\left(z_{1}\right)$ is of a classical form leading to chatter, unless $\alpha$ is small. Then, the action of the discontinuous part of the super twisting control, which was seen as an advantage over the twisting control will be attenuated. The remaining control (13) is then dominated by the continuous action $\int \dot{u}_{1} d t$ leading to slow convergence and difficulty in compensating model uncertainties. Action of a noised sensor signal is depicted in the results section (section V).

\section{EXPERIMENTAL RESULTS}

\section{A. Action of equivalent control}

Combined shoulder and elbow are controlled in regulation with the reference vector $\Theta=\left(\theta_{1}, \theta_{2}\right)=(0.87,1.04)^{T} \mathrm{rad}$. With a $0.5 \mathrm{Kg}$ load attached to the end point which represents approximately $1 / 12$ of the total mass of the robot arm. Each joint displacement is recorded to show the effect of $\tilde{u}_{e q}$ using the twisting and super twisting laws. The switching surfaces are set as: $\sigma_{1}=12 e_{1}+\dot{e_{1}}$ and $\sigma_{2}=8 e_{2}+\dot{e_{2}}$. Parameters used in the regulation problem for the twisting law are found table III. Those used in the regulation problem for the super twisting law are stated in table IV.

Control laws used in this section are the following:

$$
u=\varphi \tilde{u}_{e q}+\triangle u
$$

with $\varphi=\{0,25 \%, 50 \%, 75 \%, 100 \%\}$ and $\triangle u$ is twisting or super twisting. As stated in section II-A, model coefficients variations of joint 1 are smaller than those of joint 2 , the action of $\tilde{u}_{e q}$ on joint 1 proves to increase performance, decreasing then rising and settling times, as depicted in Figs.4(a) and 5(a). However, it appears to destabilise joint 2 in both control laws as seen in Figs.4(b) and 5(b).

In Figs.4(a) and 5(a), joint 1 performance increases with increasing $\varphi \tilde{u}_{e q}$ while joint 2 becomes over-oscillating as seen in Figs 4(b) and 5(b). For joint 2, the attenuation factor $\varphi$ is limited to $50 \%$ in order to preserve hardware integrity.

So, as model uncertainties of joint 2 are not be compensated by the control laws, convergence is not satisfied and the appropriate step in to avoid using $\tilde{u}_{e q}$. The equivalent control is only used for joint 1 , totally, i.e. $\varphi=1$.

\section{B. regulation results}

Control of joint 1 is of the form of (17). While joint 2, as the use of the equivalent control is rejected, control is established as:

$$
u=\triangle u
$$

Where $\triangle u$ is either twisting or super twisting controls. Combined movements of both joints are controlled in regulation with two reference vectors to cover an operating range $\left[\Theta_{1}, \Theta_{2}\right]$ with $\Theta_{1}=(0.69,0.69)^{T} \mathrm{rad}$ and $\Theta_{2}=$

TABLE III

REGULATION PARAMETERS OF twisting LAW

\begin{tabular}{|c|c|c|}
\hline Joint & shoulder (joint1) & elbow (joint2) \\
\hline \hline$A_{M}$ & 1.6 & 1.0 \\
$A_{m}$ & 0.65 & 0.5 \\
$U_{M}$ & 5 & 5 \\
\hline
\end{tabular}

TABLE IV

REGULATION PARAMETERS OF super twisting LAW

\begin{tabular}{|c|c|c|}
\hline Joint & shoulder (joint1) & elbow (joint2) \\
\hline \hline$\alpha$ & 0.2 & 0.25 \\
$\varepsilon_{0}$ & 0.2 & 0.2 \\
$W$ & 1.5 & 0.95 \\
$U_{M}$ & 5 & 5 \\
$\rho$ & 0.5 & 0.5 \\
\hline
\end{tabular}




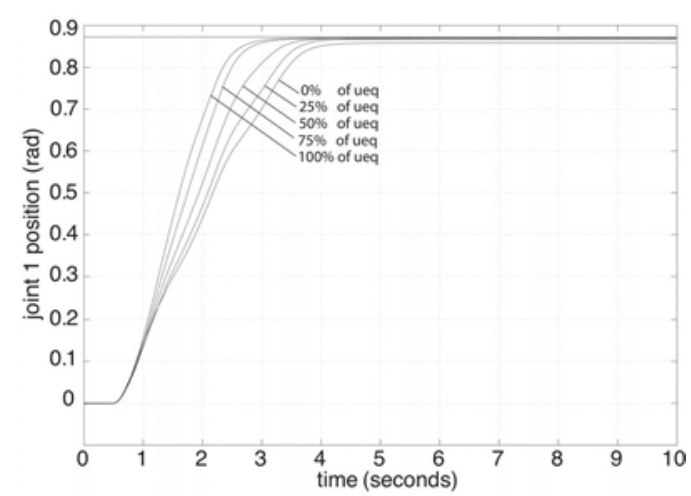

(a) joint 1 (shoulder)

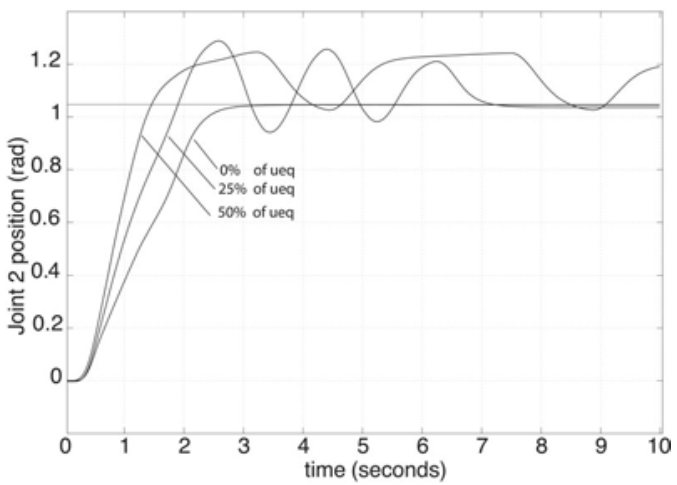

(b) joint 2 (elbow)

Fig. 4. Influence of $\tilde{u}_{e q}$ with the twisting law and $0.5 \mathrm{Kg}$ load

$(0.87,1.04)^{T} \mathrm{rad}$ with payload variation. As it can be seen in Figs. 6 and 7, both controllers can stabilize the system. Especially when equivalent control is not used on joint 2 .

The reponse delay between twisting and super twisting is insignificant on joint 1 . It should be noted that a delay of 0.75 s constant for almost all results presented, it is mainly due to: natural delay of the actuator as shown in section 2, and the $\mathrm{I} / \mathrm{P}+$ airflow pipes. Without equivalent control on joint2 twisting reponse delay is more important compared super twisting controller (Figs.6 and 13). In all case it can be noted that settling time of twisting is better than super twisting on both joints of robot. in particularly with a payload of $0.5 \mathrm{Kg}$.

Indeed, the sensor noise has limited the use of $u_{2}$ term in super twisting law. This performance has deteriorated, The remaining control (13) is then dominated by the continuous action $\int \dot{u}_{1} d t$ leading to slow convergence and difficulty in compensating model uncertainties. This can be noted noted in Figs.8 and 9, for the super twisting law presented nearby sliding surface discontinuity.

The joint 2 is considered for the action of a perturbation which represents about $22 \%$ of the reference done under the controls of both twisting and super twisting laws. The reference $(0.87,0.87)^{T} \mathrm{rad}$ with a payload of $0.5 \mathrm{Kg}$ is considered as one of the worst cases. The advantage of twisting over super twisting can again be noted before the

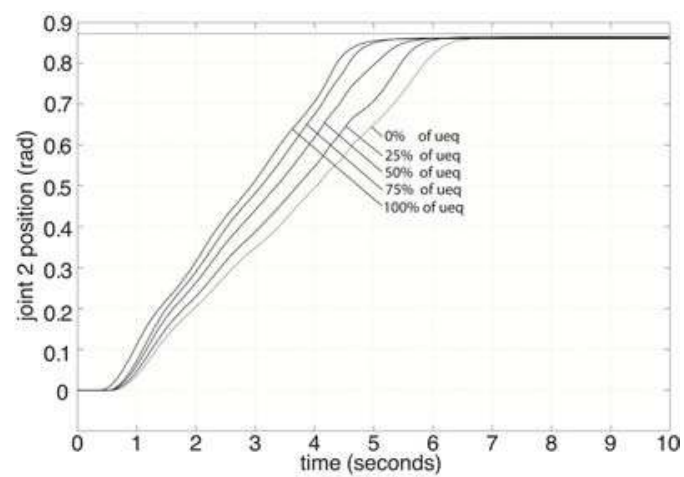

(a) joint 1 (shoulder)

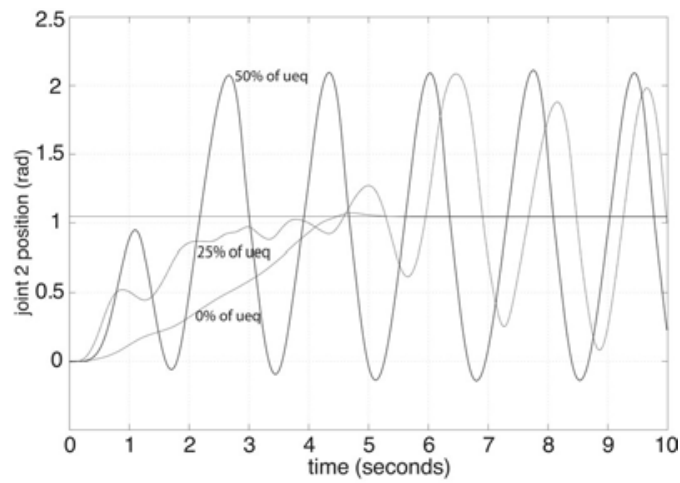

(b) joint 2 (elbow)

Fig. 5. Influence of $\tilde{u}_{e q}$ with the super twisting law and $0.5 \mathrm{~kg}$ load

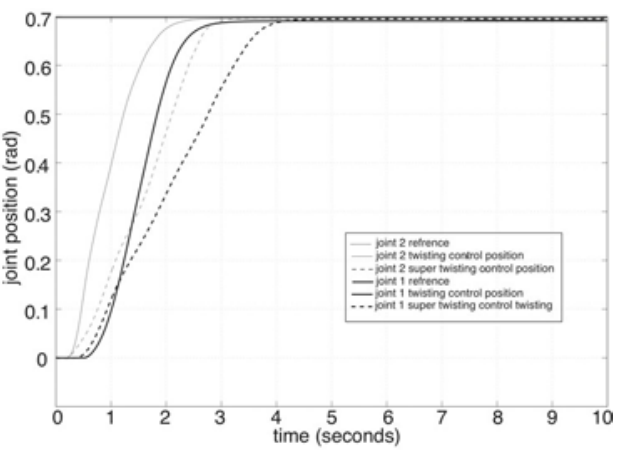

(a) $\Theta_{1}=(0.69,0.69)^{T} \mathrm{rad}$

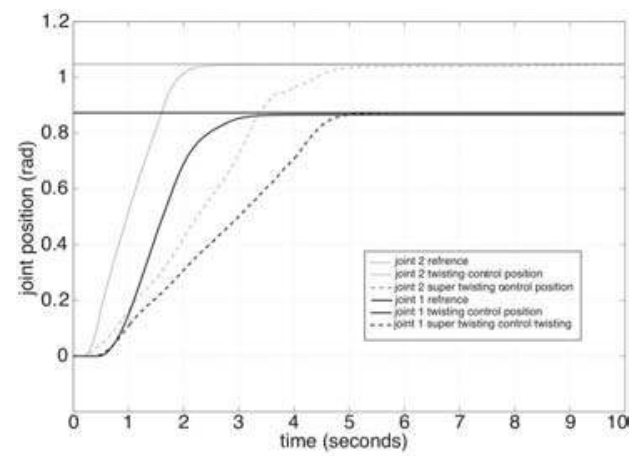

(b) $\Theta_{2}=(0.87,1.04)^{T} \mathrm{rad}$

Fig. 6. regulation joint 1 and 2, twisting and super twisting laws (no payload) 


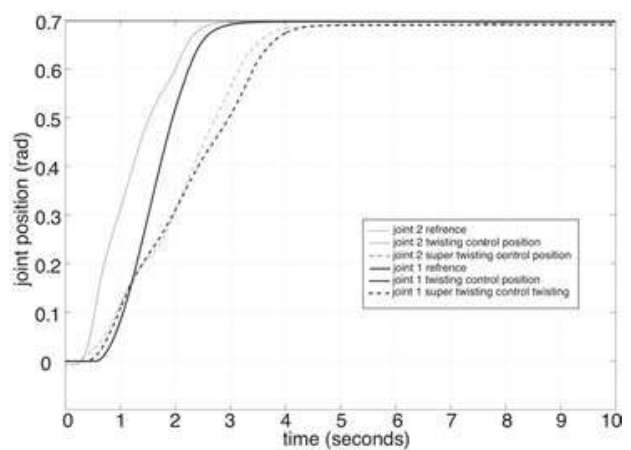

(a) $\Theta_{1}=(0.69,0.69)^{T} \mathrm{rad}$

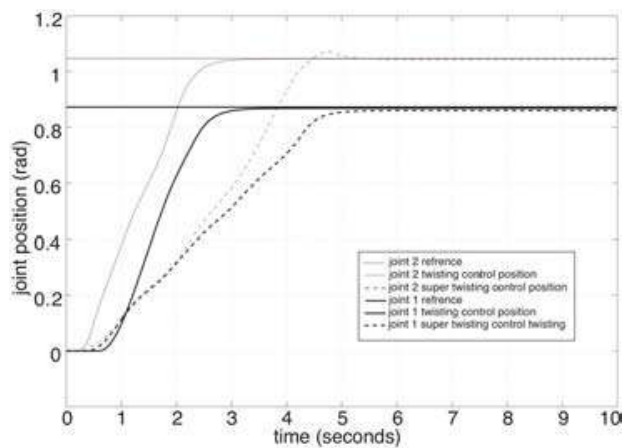

(b) $\Theta_{2}=(0.87,1.04)^{T} \mathrm{rad}$

Fig. 7. regulation joint 1 and 2, twisting and super twisting laws $(0.5 \mathrm{Kg}$ payload)

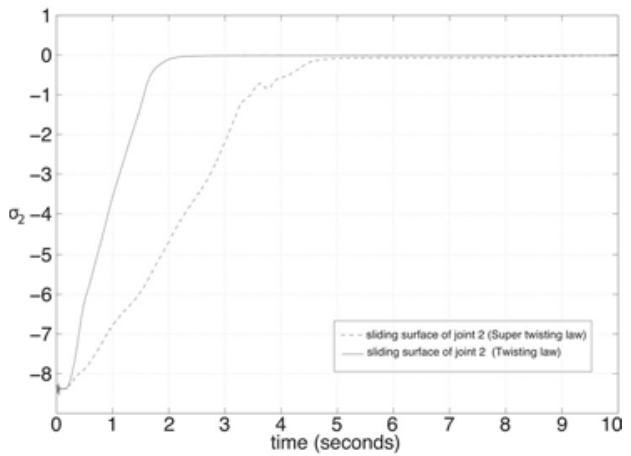

Fig. 8. sliding surface of Joint 2 twisting and super twisting laws $(0.5 \mathrm{Kg}$ payload), $\Theta_{2}=(0.87,1.04)^{T} \mathrm{rad}$

action of the perturbation. Both laws succeed in restabilising the joints responses after the perturbation is applied. In the case of the twisting controller the first overshoot (after perturbation) is limited to $24 \%$ of the reference whereas the overshoot of super twisting represents $58 \%$ of the reference, as you can seen in Fig.10. It is noted that parameters of both controllers are kept the same as for the regulation problem (table III and IV).

\section{Tracking a sinusoid}

Let us now see the ability of the laws to make joint 2 track a sinusoid. Input trajectory is considered to be: $0.3491 \sin (2 \pi f t)+0.6981 \mathrm{rad}$, with $0.1 \mathrm{~Hz}$ frequency and a payload variation. The parameters of twisting and super

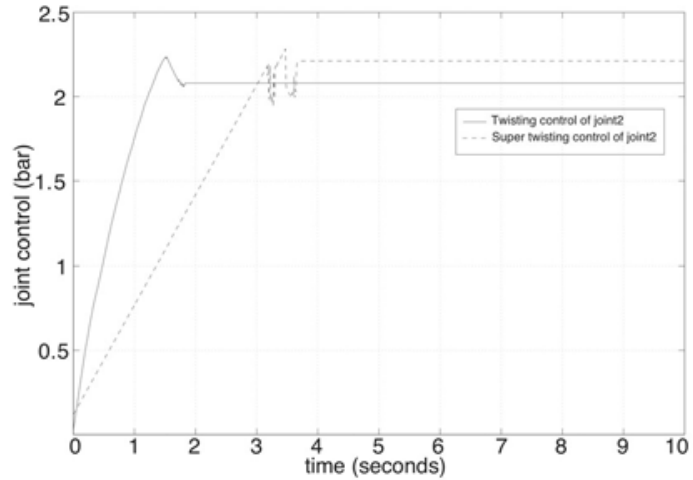

Fig. 9. twisting and super twisting laws $\left(0.5 \mathrm{Kg}\right.$ payload) joint $2, \Theta_{2}=$ $(0.87,1.04)^{T} \mathrm{rad}$

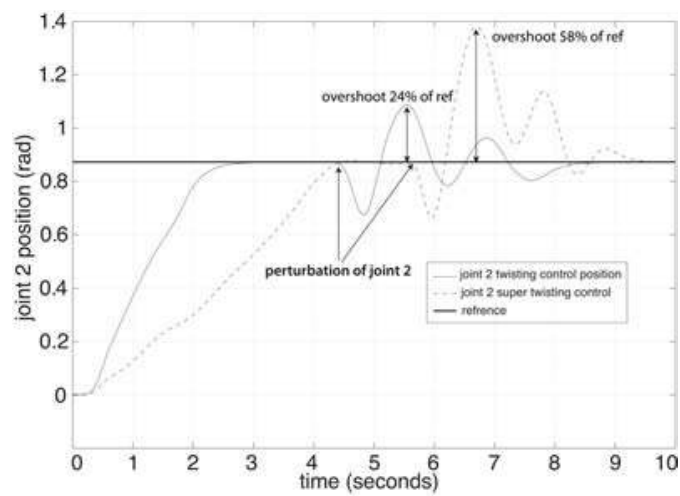

Fig. 10. Joint 2 twisting and super twisting laws (0.5Kg payload) with a perturbation for reference $(0.87,1.39)^{T} \mathrm{rad}$

twisting law are respectively indicate in table $\mathrm{V}$ and VI.

twisting and super twisting controls manage to track the sinusoid, though a more important initial delay exists for the super twisting (Figs.11). Moreover the tracking error when using a super twisting is more important than that of a twisting law, particularly when a payload is carried.
TABLE V

TRACKING PARAMETERS OF twisting LAW

\begin{tabular}{|c|c|}
\hline Joint & elbow (joint2) \\
\hline \hline$A_{M}$ & 2.41 \\
$A_{m}$ & 2.1 \\
$U_{M}$ & 5 \\
$\% u_{e q}$ & $0 \% . u_{e q}$ \\
\hline
\end{tabular}

TABLE VI

\section{TRACKING PARAMETERS OF} super twisting LAW

\begin{tabular}{|c|c|}
\hline Joint & elbow (joint2) \\
\hline \hline$\alpha$ & 0.1 \\
$\varepsilon_{0}$ & 0.1 \\
$w$ & 3 \\
$U_{M}$ & 5 \\
$\rho$ & 0.5 \\
$\% u_{e q}$ & $0 \% . u_{e q}$ \\
\hline
\end{tabular}

\section{DISCUSSION AND CONCLUSIONS}

The introduction of the equivalent control in the effective control proves to be useful if model uncertainty or parameter variations are not too far from the physical system. However, if this is not the case, the equivalent control will destabilize the system. As the joint 2 is a lot more sensitive to dynamics effects than the joint 1 , the use of the equivalent control on this joint leads to instability of robot. On the contrary its use 


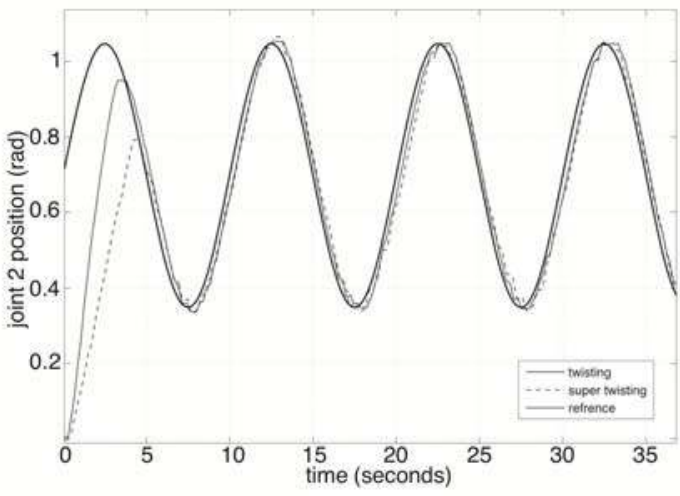

(a) $0.1 \mathrm{hz}$ without payload

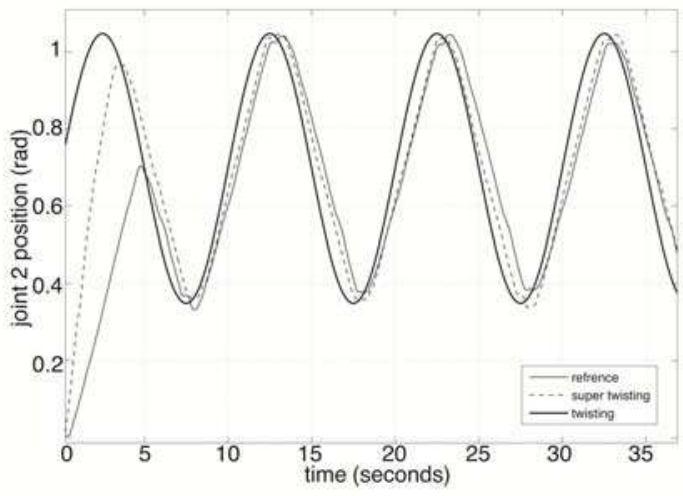

(b) $0.1 \mathrm{hz}$ with $0,5 \mathrm{Kg}$ payload

Fig. 11. twisting and super twisting in tracking a sinusoid

on the shoulder is beneficial. A payload of $0.5 \mathrm{Kg}$ is used to stress inertia and gravity effects.

The two controls of interest (twisting and super twisting) as practical controls are tested in regulation, versus a perturbation and in tracking a sinusoid. The super twisting law is too slow to present a pratical interest. It is worth noting that a payload of $0.5 \mathrm{Kg}$ is used to stress the inertia and gravity effects. Both laws succeed in restabilising the system with, however the overshoot after perturbation represents $58 \%$ of the reference with the super twisting law, whereas it is only $24 \%$ with twisting law. Input sinusoid frequency is used 0.1 $\mathrm{Hz}$ with a payload variation of $0.5 \mathrm{Kg}$. both twisting and super twisting laws despite an initial delay manage to track the input signal. It is worth noting that a more important initial delay for the super twisting law.

As a first conculsion, the equivalent control shall not be used when the system model is not finely approximated, and only a discontinous control is applied. In which case the response to 2-sliding controls becomes slow. This results confirm in part the outcome published [18]. It is thus necessary, in the future, to study the introduction of an additional term in order to reduce rising time and increase convergence speed toward the sliding surface. Also, it will be considered the relevance of the model improvements towards stability with the use of the equivalent control in the SMC.

\section{REFERENCES}

[1] J.G.F. Francis, The QR Transformation I, Comput. J., vol. 4, 1961, pp 265-271.

[2] H. Kwakernaak and R. Sivan, Modern Signals and Systems, Prentice Hall, Englewood Cliffs, NJ; 1991.

[3] D. Boley and R. Maier, "A Parallel QR Algorithm for the NonSymmetric Eigenvalue Algorithm", in Third SIAM Conference on Applied Linear Algebra, Madison, WI, 1988, pp. A20.

[4] D.G. Caldwell, G.A. Medrano-Cerda, and M.J Goodwin. "Control of pneumatic muscle actuators". IEEE Control Systems Journal, vol.15, no.1, pp.40-48, 1995.

[5] B. Verrelst, M. Van Damme and D. Lefeber. "Overview of the Lucy Project: Dynamic Stabilization of a Biped Powered by Pneumatic Artificial Muscles". Advanced Robotics, Vol.22, no.10, pp.1027-1051, 2008.

[6] C.P.Chou and B.Hannaford. "Meusurement and modeling of McKibben Pneumatic Artificial Muscles." IEEE Trans. Robotics Automation, vol.12(1), pp.90-102, 1996

[7] T.Vo Minh, T.Tjahjowidodo, H.Ramon and H.Van Brussel. "Nonlocal Memory Hysteresis in A Pneumatic Artificial Muscle (PAM)." in Proc $17^{\text {th }}$ Mediterranean Conference on Control and Automation, Thessaloniki, Greece, pp.640-645, 2009.

[8] B.Tondu and P.Lopez. (2000, Apr) "Modeling and control of McKibben artificial muscle robot actuators." Control Systems Magazine, IEEE, vol.20, no.2, pp.15-38, 2000.

[9] G.K.Klute and B.Hannaford. "Fatigue characteristics of McKibben artificial muscle Actuators." in Proc IROS-98, Victoria, BC, Canada, pp.1776-1782, 1998.

[10] N.Nakamura, M.Sekiguchi, K.Kawashima, T.Kagawa, and T.Fujita "Developing a robot arm using pneumatic artificial rubber muscles". Power transmission and motion control, Professional Engineering Publishing Ltd, Eds. C.R. Burrows and K.A.Edge, 2002.

[11] W. Perruquetti and J.P.Barbot, Sliding mode control in engineering. chapter 3: Higher-Order Sliding Modes - L. Fridman and A. Levant Marcel Dekker, New York, USA, 2002.

[12] K.D.Young, V.I.Utkin and U.Ozguner. "A control engineer's guide to sliding mode control." IEEE Trans. Control Syst. Technol, vol.7,no.3, pp.328-342, 1999.

[13] V.I.Utkin. "Variable structure systems with sliding modes." IEEE Trans. On Automatic Control, vol.22, no.2, pp.212-222, 1977.

[14] V.I.Utkin, J.Guldner, J.Shi. and M.Shijun. Sliding mode control in electromechanical systems. Taylor and Francis, UK, 1999.

[15] G.Bartolini, A.Ferrara. And E.Usai. "Chattering avoidance by second order sliding mode control." IEEE Trans. On Automatic Control, vol.43,no.2, pp.241-246, 1998.

[16] S.V.Emelyanov, S.K.Korovin, and A.Levant. "High order sliding modes in control systems." Differential equations, vol.29, no.11, pp.1627-1647, 1993.

[17] A.Levant. "Sliding order and sliding accuracy in sliding mode control." Int. Journal of Control, vol.58, no.6, pp.1247-1263, 1993.

[18] M.Chettouh, R.Toumi and M.Hamerlain. "High order sliding modes for a robot driven by pneumatic artificial rubber muscles." Int. Journ. of Robotics and Automation, vol.23, no.2, pp.88-97, 2008.

[19] S.V.Emelyanov, S.K.Korovin and L.V.Levantvosky. "A new of second order sliding algorithms." Mathmetical Modeling, vol.2, pp.89-100, 1990 (in Russian).

[20] S.V.Emelyanov, S.K.Korovin and L.V.Levantvosky. "Second order sliding modes in controlling uncertain systems." Soviet Journal of Computer and Science, vol.24, pp.63-68, 1986.

[21] S.V.Emelyanov, S.K.Korovin and L.V.Levantvosky. "Higher order sliding modes in the binary control systems." Soviet Physics, Doklady, vol.4, pp.291-293, 1986

[22] V. Boitier. "Implementation and control of a SCARA robot, actuated by McKibben pneumatic artificial muscles." PhD thesis, University of Toulouse - INSA Toulouse, Chapter 2, pp.39-81. 1996 (in French).

[23] A.F.Filippov, Differential equations with discontinuous right-hand side. Kluwer Academic Publishers, Netherlands, 1988. 